*Doutor em Direito Constitucional pela Universidade de Fortaleza (Unifor) Professor em Direito no Centro Universitário 7 de Setembro (UNI7)E-mail: marcelosampaiosiqueira@ hotmail.com

**Doutor em Direito pela Universidade Federal do Ceará (UFC)Professor em Direito no Centro Universitário $7 \mathrm{de}$ Setembro (UNI7) E-mail: alisson. melo@gmail.com

***Mestrando em Direito no Centro Universitário Christus (Unichristus) E-mail: victorfelipejus@hotmail.com

\section{A INDENIZAÇÃ̃o SUPLEMENTAR EM CASO DE RESCISÃo DO CONTRATO DE REPRESENTAÇÃO COMERCIAL}

\author{
THE SUPPLEMENTARY INDEMNIFICATION IN THE EVENT \\ OF TERMINATION OF THE COMMERCIAL REPRESENTATION \\ CONTRACT
}

\section{Marcelo Sampaio Siqueira* Álisson José Maia Melo** Victor Felipe Fernandes de Lucena***}

Como citar: SIQUEIRA, Marcelo Sampaio; MELO, Álisson José Maia; DE LUCENA, Victor Felipe Fernandes. A indenização suplementar em caso de rescisão do contrato de representação comercial. Scientia Iuris, Londrina, v. 25, n. 2, p. 44-61, jul. 2021. DOI 10.5433/21788189.2021v25n2p44. ISSN: $2178-8189$

Resumo: As mudanças impostas pela globalização econômica vêm gerando uma pressão social, com reflexos jurídicos, na interpretação das relações contratuais, inclusive nos contratos comerciais mais tradicionais. $\mathrm{O}$ presente artigo analisa, no contexto do contrato de representação comercial, a possibilidade ou não de se cobrar indenização suplementar em caso de rescisão sem justa causa, considerando o art. $27, j$, da Lei $n^{\circ} 4.886 / 65$. A partir de uma abordagem dedutiva, a pesquisa parte de uma análise das características gerais do contrato de representação comercial para, num segundo momento, avaliar a situação de rescisão contratual sem justo motivo e o impacto da falta de pré-aviso e, ao final, investigar a possibilidade de indenização suplementar na hipótese de perdas e danos superiores ao piso legal. Conclui-se que, seja numa perspectiva comparativa com a legislação espanhola e portuguesa, seja a partir da teoria do diálogo das fontes, com aplicação dos princípios da boa-fé e da função social dos contratos, a indenização suplementar no contrato de representação comercial pode acontecer, de modo excepcional, quando verificada a ocorrência de prejuízos extraordinários ou danos morais à honra e à reputação do representante.

Palavras-chave: contrato de representação comercial, rescisão, indenização legal, dano moral.

Abstract: The changes imposed by economic globalization have generated social pressure, with legal consequences, in the interpretation of contractual relations, including in more 
traditional commercial contracts. This article analyzes, in the context of the sales representation contract, the possibility or not of charging supplementary indemnity in the case of termination without cause, considering article 27, j, of Law $n^{\circ} 4.886 / 65$. Based on a deductive approach, this research begins with an analysis of the general characteristics of the sales representation contract in order to, in a second moment, evaluate the situation of contractual termination without just cause and the impact of the lack of prior notice. At the end, it investigates the possibility of supplementary indemnification in the hypothesis of losses and damages that exceed the legal floor. We conclude that, either from a comparative perspective with Spanish and Portuguese legislation, or from the theory of the dialogue of sources, applying the principles of good faith and the social function of contracts, the supplementary indemnity in the commercial representation contract may occur, in an exceptional manner, when the occurrence of extraordinary losses or moral damages to the representative's honor and reputation is verified.

Keywords: commercial representation contract, termination, legal indemnity, moral damage. 


\section{INTRODUÇÃO}

O contrato de representação comercial decerto qualifica-se como a mais importante modalidade de contratos de colaboração no âmbito da atividade empresarial no Brasil. Os contratos de colaboração são assim entendidos como aqueles contratos em que há uma estratégia ganhaganha, a estimular a cooperação das partes no esforço comum de consolidar determinados produtos em mercados específicos. Silente no Código Comercial de 1850, que tratava somente do mandato e da comissão, a evolução das práticas mercantis no Brasil levou ao desenvolvimento de um modelo antigo de parceria empresarial para a expansão de marcas e produtos em mercados nacionais, remontando aos antigos caixeiros-viajantes (SIQUEIRA; SIQUEIRA, 2018, p. 111-112).

Com os avanços da pós-modernidade e o desenvolvimento do supercapitalismo, verificase o acirramento das relações mercantis em prol da eficiência, traduzida nas pressões entre as empresas para a redução de custos, mormente nas etapas de comercialização - na qual se insere a representação comercial -, o aumento das desigualdades econômicas com a multiplicação dos perfis empresariais (da microempresa à multinacional) e a consequente potencialização das vulnerabilidades a que empresas e empresários também restam submetidos (REICH, 2007). As mudanças hodiernas nas relações socioeconômicas, inclusive no Brasil, têm ensejado a preocupação quanto à incorporação de questões sociais nas relações privadas, a exemplo da introdução da função social, dos direitos humanos e da proteção do meio ambiente, o que vem acarretando uma revisita aos tradicionais institutos do direito privado (MATIAS; NOGUEIRA, 2018; SOARES; SANT'ANNA, 2019).

Questão ainda tormentosa na prática mercantil e que resvala na jurisprudência nacional em torno dessa modalidade contratual diz respeito ao momento de extinção contratual, principalmente diante da possibilidade de rescisão antecipada, e os efeitos jurídicos decorrentes. $\mathrm{O}$ recorte específico desta investigação recai sobre os direitos do representante comercial na indenização por rescisão unilateral voluntária (sem justa causa) por culpa da empresa representada, regulada pela Lei $n^{\circ} 4.886 / 65$, modificada pelas Leis $n^{\circ} 8.420 / 92$ e 12.246/2010 (art. 27, $j$ ) e pelo Código Civil, e a possibilidade, em face de limitação legal e contratual, de se cobrar verba indenizatória suplementar, fora o mínimo de 1/12 (um doze avos ou um duodécimo) do total de comissões atualizadas auferidas durante o período de exercício da representação.

O objetivo geral da pesquisa visa a apresentar uma solução diferenciada para situações específicas de ônus excessivo para o representante, que busquem garantir o equilíbrio econômico em respeito aos princípios e regras regentes do direito contratual empresarial, em especial a função social do contrato.

Em termos metodológicos, procura-se desenvolver a pesquisa mediante uma abordagem dedutiva em pesquisa de natureza teórica e qualitativa, com emprego de material bibliográfico e documental legal como fonte. De modo auxiliar, recorre-se ainda ao estudo comparado do tema no Direito espanhol e português. Dedica-se ainda ao estudo das legislações essenciais, direitos fundamentais e princípios, a fim de elaborar uma boa análise das jurisprudências para o 
esclarecimento do tema.

No enfrentamento do problema proposto nesta investigação, observa-se inicialmente a caracterização jurídica do contrato entre representante e representada na representação comercial, após o que se enfoca a questão indenizatória oriunda da rescisão prevista pela Lei dos representantes comerciais. Posteriormente, estuda-se a questão da indenização suplementar em relação à dignidade da pessoa, de forma a fundamentar sobre a possibilidade ou não de pagamento de indenização suplementar, considerando os princípios da boa-fé objetiva e da função social do contrato.

\section{NATUREZA JURÍDICA DO CONTRATO DE REPRESENTAÇÃO COMERCIAL}

O regime jurídico do contrato de representação comercial remonta à tipificação contratual ocorrida com a legislação especial instituída pela Lei $n^{0} 4.886 / 65$, ainda vigente, com posteriores alterações legislativas pelas Leis $n^{0} 8.420 / 92$, com disciplina mais compreensiva acerca da remuneração e da exclusividade, e 12.246/2010, tratando mais especificamente da vinculação aos conselhos da categoria (MENDONÇA, 2013, p. 659-663).

O Código Civil, por sua vez, optou pela adoção da nomenclatura agência, dividindo-se a doutrina ora em identificar as duas modalidades contratuais (MARTINS, 2019, p. 224), ora em estabelecer uma relação de continência, sendo agência gênero do qual a representação seria espécie dileta para o Direito Empresarial (NEGRÃO, 2020, p. 287), ora quem até mesmo suscite tratar-se de contratos distintos, cuja natureza distintiva é a qualificação registral do contratado (ALVES, 2018, p. 128).

A relação jurídica criada na representação comercial pressupõe a existência de duas partes: a) o representado ou agenciado, a pessoa natural ou jurídica em favor de quem os negócios são intermediados e, se for o caso, quem afinal promove a entrega das mercadorias ou a realização dos serviços; e b) o representante ou agente comercial, a pessoa natural ou jurídica responsável por agenciar propostas em favor de terceiro, intermediando a transação sem adquirir por conta própria as mercadorias ou realizar a atividade contratada.

A bem da verdade, o contrato de representação comercial em sua substância nuclear equivale ao contrato de agência; entretanto, confere ao contratado mais poderes. O representante, além de demonstrar o produto e promover o negócio, também o conclui, embora mediante condição suspensiva até a anuência da empresa representada, podendo inclusive participar ativamente da execução do contrato.

Porém, há importantes vozes que buscam trazer identidade entre esses tipos contratuais: para Costa (2018), há uma coincidência da disciplina jurídica de ambos os contratos, seja do ponto de vista estático (na identificação das partes e do objeto do negócio), seja do ponto de vista dinâmico (no modus operandi de cumprimento do referido contrato), configurando-se um e o mesmo tipo; Haical (2012, p. 89 e ss.) entende ter havido equívoco do legislador quanto ao nomen iuris na Lei $\mathrm{n}^{\mathrm{o}} 4.886 / 65$ pois, a despeito de adotar o nome representante comercial, estaria disciplinando tão somente o contrato de agência. Para ambos, são improcedentes os argumentos referentes à extensão dos poderes do agente e do representante, à natureza da personalidade física ou jurídica 
do contratado, à especificação do espectro de atuação da representação comercial para atividades mercantis. Essa discussão referente à existência de diferenças entre o contrato de agência e o de representação comercial não é de todo irrelevante, especialmente em virtude do efeito jurídicolegislativo decorrente: o efeito prático disso para o Direito Civil seria a conclusão de que a Lei ${ }^{o}$ 4.886/65 teria sido derrogada tacitamente pelo Código Civil naquilo que diverge.

Entende-se haver razões suficientes para superar essa postura interpretativa. Há que se considerar que a revogação tácita deve ser interpretada de forma estrita, no sentido de exigir do legislador um compromisso terminológico que se contradiz com o silêncio do codificador; a própria LINDB requer, no art. $2^{\circ}, \S 1^{\circ}$, a regulação inteira da matéria que tratava a anterior, no que é reforçado pelo $\S 2^{\circ}$, que estabelece a vedação de revogação de lei anterior quando a lei nova estabeleça disposições gerais. Ademais, a postura tácita do Código Civil não foi de rejeição normativa; pelo contrário, o art. 721 faz alusão expressa à possibilidade de legislação especial. No âmbito da hermenêutica civilista, prevalece a ausência de palavras inúteis na legislação e, nesse sentido, a escolha do termo agente sem alusão ao instituto do contrato de representação comercial, já conhecido pela comissão responsável pela elaboração do Código Civil, aparenta uma intencionalidade do legislador; também pode-se ventilar a solução do conflito aparente de regras (antinomia) através da prevalência da lei especial anterior sobre a lei geral posterior. Por fim, devese destacar ainda o fato de que o Código Civil não cuidou de unificar toda a disciplina contratual privada, restando legislações anteriores a ela em vigor, como são os casos das Leis $n^{0}$ 6.099/74, 6.729/79 (Lei Ferrari), 8.245/91, 8.955/94 e 9.514/97, que regulamentam, respectivamente, os contratos de arrendamento mercantil, de concessão comercial de veículos automotores, de locação de imóveis urbanos, de franquia e de alienação fiduciária.

Ademais, há um elemento distintivo importante entre as disciplinas legais do representante comercial e do agente, identificado logo no início da Lei $n^{\circ} 4.886 / 65$, a saber, a exigência de registro no respectivo conselho profissional. Nesse sentido, concorda-se com Negrão (2020) quando conclui que o Código Civil aplica-se integralmente para os agentes não registrados como representantes comerciais. De um ponto de vista da evolução do Direito Comercial, há um movimento permanente de diferenciação estatutária dos diversos segmentos do mercado (CAVALLI, 2012), que não pode ser menosprezado por mera interpretação. Também sob o ponto de vista de um diálogo das fontes, há que se optar por uma solução menos radical do que a revogação tácita do estatuto do representante comercial, buscando-se a compatibilização desses regramentos; nesse sentido, as regras do contrato de agência poderão ser complementadas pelas disposições da Lei $n^{\circ}$ 4.886/65, e para essa lei as disposições do Código Civil se aplicariam supletivamente. Adota-se, portanto, a teoria de que o contrato de agência, tratado no Código Civil brasileiro, regulamenta supletivamente a atividade de representação comercial, atividade exercida de forma profissional regulada pela Lei $\mathrm{n}^{\circ}$ 4.886/65 e suas modificações legais posteriores (REQUIÃO, 1993), e dependente de registro no conselho regional.

No mesmo sentido é o entendimento do Superior Tribunal de Justiça (STJ), para quem a aplicação da Lei $n^{\circ}$ 4.886/65 tem como "pressuposto de incidência o registro no respectivo 
conselho regional, requisito estabelecido pelo microssistema normativo" (REsp 1678551/DF, Rel. Ministro Paulo de Tarso Sanseverino, Terceira Turma, julgado em 06/11/2018, DJe 27/11/2018) (BRASIL, 2018). Nesse contexto, o regramento codificado possui uma postura de generalidade e subsidiariedade em relação à legislação específica, voltada propriamente para as transações empresariais e dotada de uma principiologia própria. Aliás, o próprio Código Civil faz concessão à lei especial por força do art. 721, complementada pelas regras gerais sobre mandato e comissão, naquilo que compatível (MARTINS, 2019, p. 224).

Em razão da existência de regramentos diferenciados da representação comercial autônoma para a agência lato sensu, o enfoque da pesquisa volta-se apenas para o contrato de representação comercial stricto sensu.

A relação é regulada por contrato (manifestação bilateral de vontades), não exigindo a lei qualquer formalidade ou solenidade para sua formação, embora seja aconselhável que se faça na forma escrita, porquanto imprimirá maior segurança à relação jurídica, o que seria vantajoso para ambas as partes (BERTOLDI; RIBEIRO, 2020, seção 75.4). A contratação verbal, mais adequada para negócios informais ou microempreendimentos, gera custos de transação elevados quando da ocorrência de conflitos de interpretação da vontade das partes e apreciação das provas colhidas (NEGRÃO, 2020, p. 289), bem como quanto à qualificação da relação jurídica como trabalhista ou mercantil.

Quanto ao conteúdo do contrato, o art. 27 da Lei n ${ }^{\circ}$ 4.886/65 traz uma dezena de cláusulas obrigatórias, merecendo destaque, pela peculiaridade da contratação, a indicação das mercadorias e atividades objeto da representação (b), a definição das zonas de atuação (d) e as regras de exclusividade (g e i), inclusive se unilateral ou bilateral, e as condições de remuneração do representante (f). No que interessa à presente investigação, a cláusula referente ao prazo do contrato (c), se definido ou indeterminado, pode implicar ainda modificações quanto às indenizações no momento de eventual rescisão contratual (j) (SIQUEIRA; SIQUEIRA, 2018, p. 118).

Não há o estabelecimento de vínculo empregatício ou qualquer outra modalidade de subordinação, pois o representante comercial age com autonomia e habitualidade e com intuito mercantil (MARTINS, 2019, p. 224-225). Em relação à última característica, enquanto por um lado implica ser o proponente presumivelmente um empresário ou sociedade empresária, isso não significa que necessariamente o representante organize sua atividade econômica em formato empresarial, podendo atuar como profissional liberal (NEGRÃO, 2020, p. 290).

Além da autonomia, da habitualidade e da mercantilidade, apontam-se ainda as características de profissionalidade do representante, a delimitação geográfica atrelada com a exclusividade da representação e a remuneração ou onerosidade (MARTINS, 2019, p. 227228); a intransferibilidade, a bilateralidade, a aproximação inter alios, que reforça o papel de intermediação, e a estabilidade contratual, durabilidade ou não-eventualidade (NEGRÃO, 2020, p. 288).

Nada obstante isso, o representante fica vinculado às cláusulas contratuais e às instruções do representado em relação às possibilidade e restrições quanto à atividade a ser realizada, em 
especial a concessão de descontos nos preços ou dilatação do prazo para pagamento (BERTOLDI; RIBEIRO, 2020, seção 75.6).

O representante desenvolve atividade bem mais complexa e autônoma do que a exercida pelo procurador na execução de um simples mandato. As obrigações do representante comercial podem ser classificadas como de fazer: são espécie de prestação de serviço, cujo objetivo é demonstrar o produto ou o serviço ao pretenso comprador e, em caso de sucesso, enviar o pedido à representada. É interessante reafirmar que o representante age em nome e no interesse de outrem.

\section{A QUESTÃO DOS DIREITOS RESCISÓRIOS NO CONTRATO DE REPRESENTAÇÃO COMERCIAL}

Ao esclarecer a natureza jurídica da atividade do agente comercial e o contrato firmado entre representante comercial e empresa representada, se passa ao estudo da questão rescisória e dos direitos do representante, parte supostamente hipossuficiente. Conforme visto, o contrato de representação comercial não se constitui numa relação de trabalho, mas em relação mercantil ou interempresarial, baseada em contrato, em que o agente é um prestador de serviço da representada, e não um empregado, não lhe sendo aplicadas as regras da Consolidação das Leis do Trabalho (CLT).

O representante comercial, pessoa natural ou jurídica, deve ter sua relação com a empresa representada regida preferencialmente por um contrato escrito, com cláusulas obrigatórias. Destaca-se, neste momento, a fixação da "indenização devida ao representante pela rescisão do contrato fora dos casos previstos no artigo 35 [da Lei $n^{\circ} 4.886 / 65$ ], cujo montante não poderá ser inferior a 1/12 (um doze avos) do total da retribuição auferida durante o tempo em que exerceu a representação" (BRASIL, 1965). Esse constitui o objeto de estudo deste artigo, que visa analisar a verba rescisória devida ao representante comercial que tem o contrato rescindido sem justa causa e a possibilidade jurídica do pagamento de uma indenização suplementar, não prevista expressamente na Lei $n^{\circ} 4.886 / 65$.

A rescisão é aqui retratada, segundo os ensinamentos de Azevedo (2002), como a inexecução culposa da obrigação, acarretando ruptura do negócio jurídico, cujo descumprimento poderá ser unilateral ou bilateral. $\mathrm{O}$ que se aborda nesta pesquisa é tão somente os direitos do representante comercial na indenização por rescisão unilateral voluntária por culpa da empresa representada, quando resta devida a indenização legal ao representante comercial, sem excluir a possibilidade jurídica de uma indenização suplementar.

Assim, se a denúncia do contrato parte da empresa representada, sem fundamento nas situações previstas no art. 35 da Lei 4.886/65, haverá a ocorrência de rescisão sem justo motivo. Nesse caso, caberá à empresa representada, nos contratos de prazo indeterminado, o pagamento da indenização devidas segundo as disposições contratuais, cláusula obrigatória prevista no art. $27, j$, da Lei $\mathrm{n}^{\circ}$ 4.886/65. Por se tratar de denúncia sem causa justificada, se o contrato tiver prazo indeterminado e estiver vigente há mais de um semestre, deve ainda ser prevista garantia no contrato 
face à denúncia imotivada ou, na sua falta, cabe a concessão do pré-aviso estipulado no art. 34 da Lei $\mathrm{n}^{\mathrm{o}}$ 4.886/65, garantida a antecedência mínima de 90 (noventa) dias do art. 720 do Código Civil, além de pagar todas as comissões não pagas e pendentes, que passam a ter vencimento antecipado.

O entendimento sufragado pelo Superior Tribunal de Justiça (STJ) rechaça a aplicação do art. 34, em especial o aviso prévio, a hipóteses de denúncia motivada; para o Ministro Carlos Alberto Menezes Direito, “[n]ão seria mesmo razoável que houvesse a obrigatoriedade do aviso prévio quando uma das partes toma a iniciativa da ruptura diante de motivo justo" (REsp 417.058/ MG, Rel. Ministro Carlos Alberto Menezes Direito, Terceira Turma, julgado em 06/12/2002, DJ 10/03/2003, p. 190) (BRASIL, 2002).

Para delinear ainda mais o problema da rescisão sem justa causa do contrato de representação comercial, Siqueira e Siqueira (2018) anotam três aspectos importantes: (1) tratando-se de contrato com prazo determinado, a rescisão fundada no fim do prazo contratual implica encerramento natural do contrato, sem a possibilidade de aplicação do pré-aviso ou de indenização; (2) o art. 720 do Código Civil, a despeito de se tratar de norma geral posterior, teria modificado parcialmente o teor do art. 34 da Lei $\mathrm{n}^{\circ}$ 4.886/65, apenas no tocante ao prazo do aviso prévio, passando de 30 (trinta) para 90 (noventa) dias; e (3) para os contratos de prazo indeterminado celebrados após a vigência da reforma promovida pela Lei $n^{\circ} 8.420 / 92$, a indenização não poderá ser inferior a um duodécimo $(1 / 12)$ da soma de todas as remunerações recebidas na vigência contratual, devidamente corrigidas.

As hipóteses de denúncia por justa causa estipulam rol numerus clausus, não comportando outras situações nele não previstas. A Lei $n^{\circ} 4.886 / 65$ afasta, em dispositivo posteriormente inserido especificamente no intuito de apaziguar divergências, a situação de impedimento temporário do representante comercial em gozo de auxílio-doença (art. 45).

É interessante sempre ressaltar, quando se trata de rescisão em contrato de representação comercial por iniciativa da empresa representada, que o representante comercial tem 5 (cinco) anos para pleitear retribuições devidas e não pagas pelas empresas representadas, para o que a legislação especial (Lei $\mathrm{n}^{\circ} 4.886 / 65$ ) escolheu o rito sumário, procedimento extinto pelo Código de Processo Civil (CPC), adepto do procedimento único comum. Logo, o rito processual, considerando a atual legislação processual, para discussão de assuntos rescisórios relativos à representação comercial é o ordinário, sem prejuízo da possibilidade de ingresso nos juizados especiais, a depender da complexidade e do valor da causa.

O tema até aqui tratado serve para que melhor se sensibilize às peculiaridades da rescisão do contrato de representação comercial. Destaca-se mais uma vez, em conformidade com os tipos legais apresentados, que o representante poderá ter direito, ao ser injustamente descartado do contrato de agência, a pelo menos três verbas indenizatórias: a) por rescisão imotivada, segundo o art. 27, $j$, da Lei $n^{\circ}$ 4.886/65 e suas modificações; b) sobre os negócios úteis, de acordo com o disposto no art. 717 do Código Civil; e c) por falta de concessão do aviso prévio.

Com isso, a legislação brasileira fixa uma indenização tarifada, devida no momento da rescisão do contrato de representação comercial e segundo as circunstâncias específicas da rescisão (justa causa, pré-aviso), o que levaria a supor pela impossibilidade jurídica de uma indenização 
suplementar. Resta enfrentar essa hipótese específica, ou seja, o problema a ser resolvido diz respeito à possibilidade de aplicação de verba indenizatória complementar, além das mencionadas pela legislação, caso remanesça dano sofrido pela rescisão do contrato e ainda não reparado.

\section{CABIMENTO DA INDENIZAÇÃO SUPLEMENTAR E POSSÍVEL AFRONTA AO ART. 27, J, DA LEI No 4.886/65}

A questão central da presente pesquisa é tratar de aspectos atuais da relação contratual entre representante comercial e a empresa representada, com o intuito de avaliar a viabilidade ou não da cobrança de verba indenizatória suplementar em caso de rescisão do contrato de representação comercial. A análise deve considerar a legislação brasileira, preconizada pela citada Lei especial, que fixa de forma expressa o valor das perdas e danos em caso de rescisão do contrato nessa modalidade.

\section{1 análise comparada: o regime jurídico do contrato de agência na Espanha e em Portugal}

Esse aspecto supostamente inviabilizaria qualquer outra cobrança a título de reparação, sendo o tratamento dispensado à verba no art. $27, j$, da Lei $n^{\circ} 4.886 / 65$ semelhante ao adotado na Lei espanhola (Ley 12/1992) e na legislação portuguesa, especificamente o Decreto-Lei $n^{\circ}$ 178/86, alterado pelo Decreto-Lei $\mathrm{n}^{\mathrm{o}} 118 / 93^{1}$, que também trata do direito indenizatório aos agentes comerciais, mas com variáveis.

A legislação espanhola, com relação à indenização decorrente da rescisão injusta do contrato de representação comercial e perda da clientela, possui regramento semelhante ao contido na legislação brasileira, pois prevê expressamente em seu texto indenização em caso de rescisão e fixação do montante (arts. 28 e 29 da Ley n ${ }^{0}$ 12/1992) ${ }^{2}$. Assim, a indenização por perda da clientela, no âmbito do exercício profissional de agente comercial na Espanha, não pode exceder a média anual das remunerações recebidas pelo agente durante os últimos cinco anos ou durante todo o período em que vigorar o contrato de representação comercial.

Como aponta Jiménez Mancha (2004), a denúncia antecipada do contrato de agência visa a impedir a clientela da empresa agenciada seja mal atendida por um agente desmotivado

1 Convém mencionar que a Constituição portuguesa prevê a modalidade legislativa do Decreto-Lei, cuja competência para elaboração recai sobre o Governo parlamentarista, nos termos do art. ${ }^{\circ} 8^{\circ}$ (PORTUGAL, [2005]). O instrumento equivalente no Brasil é a medida provisória, porém não idêntico, porque tem como pressupostos específicos a relevância e a urgência da medida.

2 Ley 12/1992 (sobre Contrato de Agencia): “Artículo 28. Indemnización por clientela. 1. Cuando se extinga el contrato de agencia, sea por tiempo determinado o indefinido, el agente que hubiese aportado nuevos clientes al empresario o incrementado sensiblemente las operaciones con la clientela preexistente, tendrá derecho a una indemnización si su actividad anterior puede continuar produciendo ventajas sustanciales al empresario y resulta equitativamente procedente por la existencia de pactos de limitación de competencia, por las comisiones que pierda o por las demás circunstancias que concurran. 2. El derecho a la indemnización por clientela existe también en el caso de que el contrato se extinga por muerte o declaración de fallecimiento del agente. 3. La indemnización no podrá exceder, en ningún caso, del importe medio anual de las remuneraciones percibidas por el agente durante los últimos cinco años o, durante todo el período de duración del contrato, si éste fuese inferior. Artículo 29. Indemnización de daños y perjuicios. Sin perjuicio de la indemnización por clientela, el empresario que denuncie unilateralmente el contrato de agencia de duración indefinida, vendrá obligado a indemnizar los daños y perjuicios que, en su caso, la extinción anticipada haya causado al agente, siempre que la misma no permita la amortización de los gastos que el agente, instruido por el empresario, haya realizado para la ejecución del contrato.” (ESPANHA, 1992) 
na continuidade do ofício, quando este não comece a operar em favor de uma concorrente. Eventualmente o agente pode ter realizado investimento de vulto para alavancar sua atividade, como última chance para recuperar a confiança de seu agenciado e, ao ser surpreendido com a rescisão, quedar-se bastante prejudicado financeiramente.

No entanto, em comparação com a Lei brasileira, observa-se que a Lei espanhola difere no tratamento da indenização por perda da clientela e da indenização por danos e prejuízos, possibilitando que se conclua pela viabilidade de responsabilização contratual da representada no direito espanhol pelos dois fatos jurídicos. É interessante afirmar que o artigo 29 ao tratar da indenização de danos não traz a fixação do limite da reparação, lacuna indicativa de que essa será devida em equivalência ao dano efetivo, caso seja comprovado.

A legislação portuguesa, como previsto no artigo 33 do Decreto-Lei no 178/86, alterado pelo Decreto-Lei $n^{\circ} 118 / 93$, também possibilita a reparação dos danos sofridos pelo representante comercial por perda da clientela derivada do término injusto do contrato de trabalho, mas, ao contrário da legislação espanhola, não fixa limite para esta (LEITÃO, 2006). Assim, entende-se que caberá ao representante comercial a prova do dano sofrido pela rescisão sem justa causa do contrato de agência e o que gerou de prejuízo a perda da clientela (lucro cessante), para que seja devida a verba indenizatória.

Fazendo uma análise comparativa, observa-se que as legislações portuguesas e, principalmente, espanhola distinguem a indenização por perda da clientela da indenização por prejuízos sofridos pela rescisão injusta. Logo, há dois fatos jurídicos passíveis de reparação, tendo a legislação do Reino da Espanha fixado limites para a indenização por perda da clientela. A quadro 1 expõe de forma didática o panorama comparativo:

Quadro 1 - Análise comparativa das legislações brasileira, espanhola e portuguesa acerca do contrato de agência e representação comercial

\begin{tabular}{|c|c|c|}
\hline $\begin{array}{l}\text { DIREITO BRASILEIRO: } \\
\text { Código Civil e Lei no } 4.886 / 65\end{array}$ & $\begin{array}{l}\text { DIREITO ESPANHOL: } \\
\text { Ley } n^{\circ} 12 / 92\end{array}$ & $\begin{array}{l}\text { DIREITO PORTUGUÊS: } \\
\text { Decreto-Lei } n^{\circ} \text { 118/93 }\end{array}$ \\
\hline $\begin{array}{l}\text { - Rescisão com aviso de noventa dias } \\
\text { (artigo } 720 \text { do Código Civil) }\end{array}$ & $\begin{array}{l}\text { - Rescisão com aviso de até seis } \\
\text { meses e previsão de indenização } \\
\text { por falta de aviso }\end{array}$ & $\begin{array}{l}\text { - Aviso de até noventa dias (art. } \\
28 \text { do Decreto-Lei } n^{\circ} 178 / 86 \text { e } \\
\text { Decreto-Lei } n^{\circ} 118 / 93 \text { ) }\end{array}$ \\
\hline $\begin{array}{l}\text { - Indenização por falta de pré-aviso } \\
\text { (art. } 34 \text { da Lei no } 4.886 / 65 \text { ) }\end{array}$ & & \\
\hline $\begin{array}{l}\text { - Indenização fixada pela lei em } \\
\text { no mínimo um doze avos de todas } \\
\text { as comissões recebidas (art. } 27 \text { da } \\
\text { Lei } n^{\circ} 4.866 / 65 \text { ) - independe de } \\
\text { comprovação de dano por perda da } \\
\text { clientela. }\end{array}$ & $\begin{array}{l}\text { - Indenização por perda do cliente, } \\
\text { limitada por lei. Não pode exceder } \\
\text { a média anual das remunerações } \\
\text { recebidas pelo agente durante os } \\
\text { últimos cinco anos ou durante todo } \\
\text { o período de duração do contrato } \\
\text { (arts. } 28 \text { e } 29 \text { da Ley n }{ }^{\circ} 12 / 92 \text { ) }\end{array}$ & $\begin{array}{l}\text { - Indenização por perda do } \\
\text { cliente, não limitada por lei e } \\
\text { fixação condicionada a requisitos } \\
\text { específicos (art. } 33 \text { do Decreto- } \\
{\text { Lei n }{ }^{\circ} 178 / 86 \text { e Decreto-Lei no }}^{\circ} \\
118 / 93 \text { ) }\end{array}$ \\
\hline$-\mathrm{di}$ & - direito a reparação: irrenunciável & \\
\hline
\end{tabular}




\begin{tabular}{|l|l|l|}
$\begin{array}{l}\text { Prazo prescricional - cinco anos } \\
\text { (art. 40, parágrafo único, da Lei } n^{\circ}\end{array}$ & $\begin{array}{l}\text { Prazo prescricional - um ano (art. } \\
\text { 4.886/65) }\end{array}$ & $\begin{array}{l}\text { Prazo prescricional }- \text { um ano a } \\
\text { contar da rescisão do contrato }\end{array}$ \\
& $\begin{array}{l}\text { (art. 33 do Decreto-Lei } n^{\circ} \text { 178/86 } \\
\text { e Decreto-Lei } n^{\circ} \text { 118/93) }\end{array}$
\end{tabular}

Fonte: Elaborado pelos autores

No Brasil, a Lei $n^{\circ} 4.886 / 65$ trata apenas de verba indenizatória, sem qualquer esboço de distinção entre reparação por perda da clientela ou dano emergente. Faz-se necessário, para oferecer resposta ao problema lançado, saber o alcance da verba indenizatória devida ao agente comercial por rescisão injusta provocada pela representada e se é possível cobrar danos morais ou reparação por perda da clientela, vez que, conforme visto, o agente comercial recebe a verba indenizatória prevista no art. $27, j$, da Lei $n^{0} 4.886 / 65$, com a redação dada pela Lei $n^{\circ} 8.420 / 92$, como um piso legal, o que, por si só, ante à falta de menção expressa, não restringiria a cobrança de indenização por eventuais danos remanescentes comprovadamente sofridos.

Numa análise superficial da hipótese legal, o intérprete pode ser tentado a concluir que o valor tratado no art. 27, $j$, engloba todos os prejuízos do representante. É bem verdade que a legislação brasileira não traz a distinção contida nos artigos 28 e 29 da legislação espanhola, mas desde já se afirma que a regra brasileira fala de indenização mínima pela rescisão injusta, sem vedar expressamente a indenização suplementar. A jurisprudência brasileira costuma consagrar como verba reparatória devida ao representante as tratadas nos art. 27, $j$, da Lei $n^{\circ}$ 4.886/65, além aquela devida pelo descumprimento do aviso prévio, nos termos do art. 34. Veja-se o entendimento do STJ nesse sentido, cuja ementa se transcreve a seguir:

RECURSO ESPECIAL. AÇÃO DE COBRANÇA DE COMISSÕES E VERBAS INDENIZATÓRIAS DECORRENTES DE CONTRATO DE REPRESENTAÇÃO COMERCIAL AUTÔNOMA. AVISO PRÉVIO INDENIZADO E INDENIZAÇÃO DE UM DOZE AVOS. JUSTA CAUSA DA RESCISÃO UNILATERAL (FORÇA MAIOR) NÃO CONFIGURADA. 1. Nos termos do artigo 34 da Lei 4.886/65, a denúncia injustificada, por qualquer das partes, do contrato de representação ajustado por tempo indeterminado e que haja vigorado por mais de seis meses, obriga o denunciante (salvo outra garantia convencionada) à concessão de aviso prévio de trinta dias ou ao pagamento de importância igual a um terço das comissões auferidas pelo representante, nos três meses anteriores. 2. Outrossim, ainda que se trate de contrato por tempo certo, caso a rescisão injustificada ocorra por iniciativa do representado, será devida ao representante (parte vulnerável da relação jurídica) indenização equivalente a um doze avos do total da retribuição auferida durante o tempo em que exercera a representação (artigo 27, letra “j”, da Lei 4.886/65). 3. Desse modo, sob a ótica do representante, as referidas verbas (aviso prévio e indenização de um doze avos) ser-lhe-ão devidas quando inexistente justa causa para a rescisão contratual de iniciativa do representado. [...] 6. Recurso especial provido, a fim de julgar procedente a pretensão do representado de cobrança das comissões pendentes e das verbas rescisórias devidas. (REsp 1341605/PR, Rel. Ministro Luis Felipe Salomão, Quarta Turma, julgado em 10/10/2017, DJe 06/11/2017) (BRASIL, 2017). 
No entanto, há outros entendimentos jurisprudenciais que sugerem a possibilidade de ocorrência de danos morais, desde que reste comprovada a ofensa e não se refiram ao risco inerente ao negócio; por exemplo, danos à honra e à imagem do representante comercial. A questão é analisar se é coerente o entendimento de que a legislação brasileira só permite a indenização prevista pelo citado art. $27, j$, e, excepcionalmente, pelo art. 34 , ou, em se tratando de ilicitude contratual (rescisão injusta), se é possível a aplicação subsidiária dos arts. 402 e seguintes do Código Civil brasileiro, que tratam das perdas e danos.

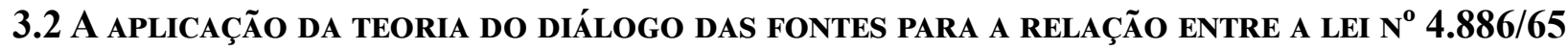 E O CÓDIGO CIVIL E A INCIDÊNCIA DOS PRINCÍPIOS DA BOA-FÉ E DA FUNÇÃO SOCIAL DOS CONTRATOS}

Cláudia Lima Marques e Bruno Miragem (2012) expõem que não pode o Poder Judiciário, ao analisar conflito entre regras, desconsiderar as diferenças entre as partes envolvidas e o diálogo das fontes, sob pena de proferir uma decisão injusta e tecnicamente condenável. Através do diálogo das fontes, é possível coadunar-se o microssistema da representação comercial autônoma com a codificação civilista, pretensamente integradora das obrigações civis e comerciais, para se reconhecer a insuficiência do microssistema em situações limítrofes de desigualdade na vulnerabilidade negocial a implicar a intromissão do Código Civil como válvula de escape, em um diálogo sistemático de complementariedade e subsidiariedade (MARQUES, 2004, p. 45).

O princípio da boa-fé objetiva, que traduz a necessidade de que as partes ajam com lealdade, constitui um princípio geral do Direito Civil, cláusula geral que acompanha todas as fases do negócio jurídico - dos pré-contratos à sua execução - à qual todos os atos jurídicos regulados pelo Código Civil devem guardar respeito. Esse princípio estabelece padrões éticos a serem seguidos pelas partes, favorecendo o resguardo de um padrão de correção e equidade na relação jurídica. Antônio Manuel da Rocha e Menezes Cordeiro (1984, p. 1298), sobre o referido princípio, arremata que na boa-fé, distinta da equidade, jaz a ideia de proteção da confiança. Araújo (2007, p. 576), ao tratar da boa-fé e da teologia contratual, acrescenta:

[...] por outro lado, trata-se também de saber, mais especificamente, se o princípio da boa fé contratual representa um alicerce tão sólido que ele seja susceptível de apoiar até a integração de lacunas, já não nos termos mais restritivos (e menos compagináveis com a discricionariedade judicial) da visão neo formalista; mas trata-se também de saber se, prosseguindo por uma metodologia contextualista, é possível ao intérprete lançar mão do princípio da boa fé contratual para desconsiderar o sentido explícito de estipulações e a vontade das partes, mormente quando não estejam em causa possibilidades de perversão iníqua das finalidades contratuais, quando não fique comprometido o fim comum das partes ou sejam feridas as legítimas expectativas da contraparte - e isto sobretudo se levarmos em conta que a boa-fé pode ser interpretada como reflexo de uma contínuo de responsabilidade de uma parte para com a outra dentro de um contrato, numa espécie de intersecção entre egoísmo e altruísmo. 
A rescisão sem justa causa é permitida na legislação que regula a atividade de representação comercial no Brasil. A boa-fé objetiva não se sustenta se o posicionamento das partes antes e depois do negócio não se mantiver constante, significando que é atentatória a esse princípio a ocorrência de ganho desproporcional de um dos envolvidos em relação ao outro. É o que acontece na hipótese sob exame: a empresa representada, considerando a suposta e frequente vulnerabilidade econômica do representante comercial na prática, não age com lealdade quando, ao distratar contrato de representação, paga apenas a indenização mínima prevista na legislação, um doze avos de todas as comissões recebidas no período, e se omite na reparação em caso de dano moral ou pela perda de clientela.

Ao se fazer uma análise da natureza jurídica da indenização prevista na legislação especial, afirma-se que tem natureza patrimonial, não se identificando qualquer impedimento legal ao pleito de eventual representante prejudicado, caso tenha prova do ato ilícito e da ocorrência do nexo de causalidade e dano, que vise à reparação pelo dano moral. A legislação brasileira não regula expressamente a indenização por perda da clientela, tratada na legislação portuguesa e espanhola, mas regula expressamente a indenização por rescisão injusta de contrato de representação, levando a crer que o piso reparatório deva incluir a referida perda. A questão que permanece indefinida é quando o valor mínimo é insuficiente para reparar os prejuízos, isto é, se o ganho do representado pela clientela desenvolvida é superior ao valor indenizado.

A questão é complexa, já que a finalidade da legislação brasileira, ao fixar a indenização, é demarcar a disparidade contratual do representante em face da empresa, de maneira que não enfrente perda patrimonial significativa por rescisão imotivada. Mas tal explicação não responde ao questionamento lançado, e o fato é que o valor mínimo estabelecido a título de indenização em caso de rescisão pode não ser suficiente para reparar por completo os danos sofridos pelo representante vítima do ilícito.

Cita-se também, pela pertinência com a fundamentação ora apresentada, a aplicação do princípio da função social do contrato previsto no artigo 421 do Código Civil, que impede o ganho desproporcional de uma parte em detrimento da outra. Afirma-se, por oportuno, que as alterações introduzidas no ordenamento brasileiro pela Lei $n^{\circ} 13.874 / 2019$, que trata sobre o desenvolvimento econômico e altera o paradigma interpretativo do princípio da função social do contrato, ao incluir o parágrafo único no artigo 421 do Código Civil, não afasta o entendimento do Enunciado 22 da I Jornada de Direito Civil, do Conselho da Justiça Federal e do Superior Tribunal de Justiça (CJF/STJ), de que a função social do contrato constitui cláusula geral que reforça o princípio da conservação do contrato, assegurando trocas úteis e justas.

Em síntese, a defesa da reparação suplementar ao representante comercial, desde que provada a insuficiência da reparação determinada pela lei (cláusula obrigatória no contrato), é medida de justiça, não sendo a complementação indenizatória atentatória ao princípio da intervenção mínima ou da excepcionalidade da revisão contratual. Na verdade, a escorreita reparação de danos ora tratada não constitui revisão da relação obrigacional.

Com isso, percebe-se que embora o contrato de representação comercial constitua relação 
privada, na qual, por via de regra, o Estado não deverá intervir, sendo exceção a revisão contratual, deve ser observada a situação de dependência econômica do representante comercial em face da empresa representada e, por via de consequência, ser observada, por aplicação subsidiária, já que se está tratando de responsabilidade contratual, a regra disposta no artigo 944, caput, do Código Civil, a qual estabelece que "a indenização mede-se pela extensão do dano".

Pelo exposto, defende-se a possibilidade, conquanto excepcional, da indenização suplementar à prevista no art. $27, j$, da Lei 4.886/65, ainda que a título de dano patrimonial ou moral, devendo o agente comercial comprovar o dano suplementar sofrido e a ser reparado, dependendo a referida indenização suplementar de prova correspondente, de modo que o ônus probatório, nesse ponto, recai sobre o representante comercial. Contudo, fogem da conotação de dano reparável o denominado fortuito interno, já que o contrato de representação comercial é em sua essência um contrato de resultado, cuja remuneração é proporcional às vendas e, portanto, o risco das negociações é inerente ao negócio jurídico.

Ressalta-se, mais uma vez, que a Lei $\mathrm{n}^{\circ}$ 4.886/65 informa que a verba rescisória tratada no art. 27, j, constitui o mínimo rescisório, sendo devida independentemente da comprovação de dano, assemelhando-se à verba indenizatória por perda da clientela prevista na legislação portuguesa e espanhola. Logo, caso se prove ser a verba legal indenizatória insuficiente para reparar todos os prejuízos, nada impede o prejudicado de requerer quantia suplementar a título de perdas e danos, cabendo-lhe contudo comprovar o dano suplementar, isto é, em medida superior ao fixado pela lei, cuja previsão contratual é obrigatória. É salutar acrescentar que a fixação de verba suplementar por perda da clientela tem natureza de lucro cessante, podendo ser considerada renda. Tal conclusão é importante devido à incidência ou não de imposto de renda tendo como fato gerador a reparação paga.

Já o dano moral, cuja previsão não deve ser excluída, fica condicionado ao preenchimento de todos os requisitos legais para sua caracterização, não sendo a simples rescisão contratual suficiente para que isso ocorra. Exige-se ato comissivo do autor do dano que importe abalo na dignidade da pessoa do representante, isto é, o reconhecimento da indenização por danos morais pelas instâncias ordinárias, considerando que a questão fática não pode ser discutida no STJ, só pode ocorrer se restar comprovado abalo à imagem e à credibilidade da representante comercial perante a sociedade:

AGRAVO REGIMENTAL NO AGRAVO EM RECURSO ESPECIAL. AÇÃO DE INDENIZAÇÃO. REPRESENTAÇÃO COMERCIAL. RESCISÃO DO CONTRATO SEM JUSTA CAUSA. AGRAVO REGIMENTAL DESPROVIDO. [...] 3. A indenização por danos morais foi reconhecida pelas instâncias ordinárias, ao argumento de ter havido abalo à imagem e à credibilidade da representante comercial perante a sociedade. Para infirmar as conclusões da Corte estadual seria imprescindível o revolvimento do conjunto probatório dos autos, o que é inadmissível em recurso especial. Aplicação da Súmula 7/STJ. [...] (AgRg no AREsp 752.917/MS, Rel. Ministro Marco Aurélio Bellizze, Terceira Turma, julgado em 03/11/2015, DJe 16/11/2015) (BRASIL, 2015). 
A aplicação é excepcional e depende do exame das circunstâncias do caso concreto a ser realizado nas instâncias ordinárias. De todo modo, o STJ não vislumbrou conflitos ou inconveniências na cumulação da indenização legal com a indenização por danos morais, a sinalizar a plausibilidade também da tese de indenização suplementar por extrapolação de danos materiais.

\section{CONSIDERAÇÕES FINAIS}

A partir do desenvolvimento da pesquisa, é possível concluir que há uma necessidade não apenas de atualização da legislação pertinente à representação comercial autônoma, mas também a revisita às relações jurídicas mercantis estabelecidas no contexto desse contrato, segundo as características e vulnerabilidades das partes envolvidas. Embora o Código Civil tenha disciplinado acerca do contrato de agência, este é gênero do qual a representação comercial seria uma espécie, dotada de microssistema próprio.

A aplicação do Código Civil se dá de modo subsidiário, sem prejuízo de que determinados dispositivos possam afetar diretamente a interpretação da Lei $\mathrm{n}^{0}$ 4.886/65, em claro diálogo sistemático de coerência entre as fontes legislativas. Embora trate-se de contrato sinalagmático e dotado de onerosidade de resultados, há riscos envolvidos para o sucesso da execução do contrato que podem escapar ao fortuito interno do negócio realizado pelo representante comercial, seja como pessoa física ou jurídica, em maior ou menor nível de organização. Nesse tocante, a vulnerabilidade do representante comercial pode transparecer uma situação de disparidade contratual.

As indenizações previstas no microssistema legislativo da representação comercial funcionam como pisos legais, em favor do representante comercial, destacando uma finalidade sistêmica em favor dessa parte do negócio, embora se busque trazer uma posição isonômica de autonomia da vontade entre as partes contratantes. Considerando a possibilidade de rescisão sem justo motivo, agravada ainda mais com o pré-aviso indenizado, pelo qual o representante comercial esteja sujeito à desagradável surpresa diante de empréstimos contraídos para alavancar seu negócio, cogita-se a possibilidade de indenização suplementar.

A fundamentação em favor dessa tese gira em torno de três abordagens. Na primeira, mediante análise comparada, as legislações de Portugal e Espanha referentes ao contrato de agência não estabelecem pisos, mas a atenção ao valor do prejuízo sofrido. Em segundo lugar, a teoria do diálogo das fontes permite uma dinâmica de complementariedade e subsidiariedade entre o regime específico da representação comercial e a codificação civil unificadora das obrigações civis e comerciais. Por fim, a aplicação dos princípio da boa-fé objetiva e da função social dos contratos ingressam para proteger a confiança da representante comercial que é surpreendida com a rescisão unilateral injustificada e garantir a continuidade da atividade econômica por ela realizada.

Caso se prove que a verba legal indenizatória devida ao representante por rescisão injusta não é suficiente para reparar todos os prejuízos, nada impede o prejudicado de requerer quantia suplementar a título de perdas e danos, cabendo-lhe contudo comprovar o dano suplementar, isto é, em medida superior ao fixado pela lei, cuja previsão contratual é obrigatória. Aplica-se esta conclusão à reparação por dano moral. 


\section{REFERÊNCIAS}

ALVES, Elton Nunes José. A disciplina jurídica dos contratos de representação comercial autônoma e agência. Revista Brasileira de Direito Empresarial, Salvador, v. 4, n. 1, p. 112131, jan./jun. 2018. Disponível em: https://www.indexlaw.org/index.php/direitoempresarial/ article/view/4210. Acesso em: 24 mar. 2020.

ARAÚJO, Fernando. Teoria econômica do contrato. Lisboa: Almedina, 2007.

AZEVEDO, Álvaro Villaça. Teoria geral dos contratos típicos e atípicos. São Paulo: Atlas, 2002.

BERTOLDI, Marcelo M.; RIBEIRO, Marcia Carla Pereira. Curso avançado de direito comercial. 11. ed. São Paulo: Thomson Reuters Brasil, 2020. E-book. Disponível em: ????. Acesso em: ????

BRASIL. Lei $n^{\mathbf{0}} \mathbf{4 . 8 8 6}$, de 9 de dezembro de 1965. Regula as atividades dos representantes comerciais autônomos. Brasília, DF: Presidência da República, 1965. Disponível em: http:// www.planalto.gov.br/ccivil_03/leis/14886.htm. Acesso em: 24 mar. 2020.

BRASIL. Superior Tribunal de Justiça (3. Turma). Agravo Regimental no Agravo em Recurso Especial 752917/MS. Agravo Regimental no Agravo em Recurso Especial. Ação de Indenização. Representação Comercial. Rescisão do contrato sem justa causa. Agravo Regimental desprovido. Agravante: Kanaflex S/A Indústria de Plásticos. Agravados: Repita Representação Comercial LTDA e Nilton Miranda Pita. Relator: Min. Marco Aurélio Bellizze. Julgado em: 3 de novembro de 2015. Disponível em: https://www.stj.jus.br/. Acesso em: 24 mar. 2020.

BRASIL. Superior Tribunal de Justiça (3. Turma). Recurso Especial 417.058/MG. Contrato de representação comercial. Rompimento do contrato pelo representante diante da ausência de pagamento de comissões pela representada. Interpretação do art. 34 da Lei $n^{\circ}$ 4.886/65. Recurso especial não conhecido. Recorrente: Flávio Representações Ltda. Recorrido: Caderbrás Produtos de Papel S/A. Relator: Min. Carlos Alberto Menezes Direito. Julgado em: 6 de dezembro de 2002. Disponível em: https://www.stj.jus.br/. Acesso em: 24 mar. 2020.

BRASIL. Superior Tribunal de Justiça (3. Turma). Recurso Especial 1.678.551/DF. Recurso Especial. Direito Empresarial. Representação comercial. Inaplicabilidade do regime jurídico previsto na Lei 4.886/65 a não inscritos no respectivo conselho regional. Atividade que não exige qualificação técnica específica. A ausência de registro não autoriza a recusa ao pagamento por serviços efetivamente prestados. Relação regida pelo Código Civil. Recorrente: Rádio Eldorado Ltda. Recorrido: New Business Representação Comercial de Meios de Comunicação EIRELI - EPP. Rel. Min. Paulo de Tarso Sanseverino. Julgado em: 6 nov. 2018. Disponível em: https:// www.stj.jus.br/. Acesso em: 24 mar. 2020.

BRASIL. Superior Tribunal de Justiça (4. Turma). Recurso Especial 1.341.605/PR. Recurso Especial. Ação de cobrança de comissões e verbas indenizatórias decorrentes de contrato de representação comercial autônoma. Aviso prévio indenizado e indenização de um doze avos. Justa causa da rescisão unilateral (força maior) não configurada. Recorrente: Godoy e Companhia LTDA Comércio e Representações. Recorrido: Kepler Weber Industrial S/A. Relator: Min. Luis Felipe Salomão. Julgado em: 10 de outubro de 2017. Disponível em: https://www.stj. 
jus.br/. Acesso em: 24 mar. 2020.

CAVALLI, Cassio. Direito comercial: passado, presente e futuro. Rio de Janeiro: Elsevier, 2012.

CORDEIRO, Antônio Manuel da Rocha e Menezes. Da boa fé no direito civil. Lisboa: Almedina, 1984.

COSTA, André Brandão Nery. Efeitos legais do conflito tipológico entre o contrato de agência e o de representação comercial autônoma. Revista de Direito Privado, São Paulo, ano 19, n. 96, p. 43-76, dez. 2018.

ESPANHA. Ley 12/1992, de 27 de mayo, sobre Contrato de Agencia. Madrid: Monarquia Real, 1992. Disponível em: https://www.boe.es/eli/es/1/1992/05/27/12/con. Acesso em: 24 mar. 2020.

HAICAL, Gustavo. O contrato de agência: seus elementos tipificadores e efeitos jurídicos. São Paulo: Revista dos Tribunais, 2012.

JIMÉNEZ MANCHA, Juan Carlos. Indemnizaciones derivadas de la resolución del contrato de agencia: análisis jurisprudencial y crítico. Revista de Derecho Privado, Madrid, año 88, n. 6, p. 787-820, nov./dic. 2004.

LEITÃO, Luís Manuel Teles de Menezes. A indemnização de clientela no contrato de agência. Lisboa: Almedina, 2006.

MARQUES, Cláudia Lima. Superação das antinomias pelo diálogo das fontes: o modelo brasileiro de coexistência entre o Código de Defesa do Consumidor e o Código Civil de 2002. Revista da Esmese, Aracaju, n. 7, Doutrina, p. 15-54, 2004. Disponível em: https:/core.ac.uk/ download/pdf/79073279.pdf. Acesso em: 24 mar. 2020.

MARQUES, Cláudia Lima; MIRAGEM, Bruno. O novo direito privado e a proteção dos vulneráveis. São Paulo: RT, 2012.

MARTINS, Fran. Curso de direito comercial: contratos e obrigações comerciais. 19. ed. Atualizada por Gustavo Saad Diniz. Rio de Janeiro: Forense, 2019.

MATIAS, João Luis Nogueira; NOGUEIRA, Mônica de Sá Pinto. Empresa contemporânea e a proteção aos direitos humanos. Revista Jurídica da FA7, Fortaleza, v. 15, n. 1, p. 115-126, jan./jun. 2018. Disponível em: https://periodicos.uni7.edu.br/index.php/revistajuridica/article/ view/559. Acesso em: 24 mar. 2020.

MENDONÇA, Vinícius de Carvalho P. O contrato de representação comercial na visão dos tribunais superiores brasileiros. Revista da Faculdade de Direito da UFMG, Belo Horizonte, n. 62, p. 657-701, jan./jun. 2013. Disponível em: https://www.direito.ufmg.br/revista/index.php/ revista/article/view/P.0304-2340.2013v62p657. Acesso em: 24 mar. 2020.

NEGRÃO, Ricardo. Curso de direito comercial e de empresa: títulos de crédito e contratos empresariais. 9. ed. São Paulo: Saraiva, 2020.

PORTUGAL. [Constituição (1974)]. VII Revisão Constitucional. Lisboa: Assembleia Constituinte, [2005]. Disponível em: https://www.parlamento.pt/Legislacao/paginas/ 
constituicaorepublicaportuguesa.aspx. Acesso em: 24 mar. 2020.

REICH, Robert. Supercapitalism: the transformation of business, democracy, and everyday life. New York: A. A. Knopf, 2007.

REQUIÃO, Rubens. Do representante comercial. 4. ed. Rio de Janeiro: Forense, 1993.

SIQUEIRA, Marcelo Sampaio; SIQUEIRA, Natercia Sampaio. A relativização da quitação da verba indenizatória no contrato de agência à luz do direito brasileiro. Revista de Direito Econômico e Socioambiental, Curitiba, v. 9, n. 2, p. 109-139, maio/ago. 2018. Disponível em: https://dialnet.unirioja.es/descarga/articulo/6811007.pdf. Acesso em: 24 mar. 2020.

SOARES, Natália de Moura; SANT'ANNA, Leonardo da Silva. A função social dos contratos empresariais: análise de julgados do TJRJ entre 2014 e 2016. Scientia Iuris, Londrina, v. 23, n. 3, set./dez. 2019. Disponível em: http://www.uel.br/revistas/uel/index.php/iuris/article/view/107. Acesso em: 24 mar. 2020.

Como citar: SIQUEIRA, Marcelo Sampaio; MELO, Álisson José Maia; DE LUCENA, Victor Felipe Fernandes. A indenização suplementar em caso de rescisão do contrato de representação comercial. Scientia Iuris, Londrina, v. 25, n. 2, p. 44-61, jul. 2021. DOI 10.5433/21788189.2021v25n2p44. ISSN: $2178-8189$

Recebido em 24/08/2020

Aprovado em 13/07/2021 